\title{
Alcohol consumption in Estonia and Finland: Finbalt survey 1994-2006
}

\author{
Kersti Pärna*1,2, Kaja Rahu2,3, Satu Helakorpi and Mare Tekkel2,3
}

\begin{abstract}
Background: Alcohol consumption has been regarded as an important contributor to the high premature mortality rates. The objective of this paper was to provide an overview and comparison of alcohol consumption and its sociodemographic determinants among adults in Estonia and Finland.

Methods: The study was based on a 25-64-year-old subsample of nationally representative postal cross-sectional surveys conducted in Estonia ( $n=10,340)$ and Finland $(n=19,672)$ during 1994-2006. Abstinence, frequency, and the amount of alcohol consumed were examined. Logistic regression models were used to test the socio-demographic differences in alcohol consumption at least once a week. The effect of socio-demographic factors on pure alcohol consumed per week was calculated using linear regression.

Results: The proportion of abstainers was 1.5 times higher among women than men in both countries. Throughout the study period, the amount of alcohol consumed per week increased for both genders in Estonia and for women in Finland, but was stable for men in Finland. In the final study year, medium risk amount of alcohol consumed per week was nearly 1.5 times higher among men in Estonia than in Finland, but about half that among women in Estonia than in Finland. Compared to ethnic majority in Estonia, alcohol consumption at least once a week was lower among men, but amount of pure alcohol drunk per week was higher among women of ethnic minority. In Finland, alcohol consumption at least once a week was more prevalent among women of ethnic minority, but the amount of pure alcohol drunk per week was lower for both gender groups of ethnic minority. Compared to married/cohabiting respondents, alcohol consumption at least once a week was less pronounced among single respondents in Finland, divorced or separated women in both countries, and widowed respondents in Estonia. Greater amount of alcohol consumed per week was more prevalent among single and divorced or separated respondents in Finland, but only among divorced or separated men in Estonia. Frequency of alcohol consumption was lower among less educated than higher educated respondents in Finland, but not in Estonia. The amount of consumed alcohol per week was higher among less educated men in Estonia, but lower among women with basic education in Finland.

Conclusions: Alcohol consumption has increased in Estonia and Finland. National alcohol policies should reflect findings of alcohol epidemiology in order to introduce measures that will reduce alcohol related harm in the population effectively.
\end{abstract}

\section{Background}

Estonia and Finland, two neighbouring countries in the Baltic Sea region, are different in certain aspects of their economic and social conditions. A former Soviet country, Estonia belongs to the group of Eastern European countries that share similar political histories and public health problems. The collapse of the Soviet Union in 1991 had enormous implications for health and for the politi-

*Correspondence: kersti.parna@ut.ee

1 Department of Public Health, University of Tartu, Estonia

Full list of author information is available at the end of the article cal and economic transition during the succeeding years. Finland, however, belongs to the Nordic countries, known as well-developed welfare states characterized by a high standard of living and effective social policies [1].

Life expectancy at birth in Estonia was 60.5 for men and 72.8 for women in 1994 and thereafter started to rise. By 2006 average life expectancy was 67.4 years for men and 78.5 years for women [2]. The corresponding figures in Finland rose steadily from 73.0 for men and 80.4 for women in 1994 to 76.0 and 83.2 in 2006 , respectively [3]. 
It is estimated that alcohol consumption is responsible for about $4 \%$ of the total disease burden in the world [4]. While regular light to moderate alcohol intake is associated with some reduction in total mortality $[5,6]$, heavy drinking has been regarded as an important contributor to the high premature mortality rates in central and eastern Europe, particularly in the countries of the former Soviet Union [7-11]. On a national level, the severity of alcohol-related consequences depends on the frequency and volume of alcohol consumption over time and the patterns of drinking [11]. Traditional patterns in Estonia and Finland are characterized by their vodka and beer drinking cultures, non-daily drinking, irregular binge drinking episodes (e.g. during weekends and festivities), and their acceptance of public drunkenness [11]. In Finland, an additional important factor was the opening of borders (south with Estonia and east with Russia) at the beginning of the 1990s, which led to a rapid increase in tourist-imported alcoholic beverages contributing to aggregate alcohol consumption [12].

In 1994, total adult (15+ years) per capita alcohol consumption was about 8 litres per year in Estonia and Finland, and it has increased by 2004 to 16 and 10 litres, respectively [3]. Thus, there was an abrupt increase in the recorded adult alcohol consumption per capita in Estonia but not in Finland in 1994-2004. Moreover, the standardized death rate (SDR) from chronic liver disease and cirrhosis, for instance, almost doubled from 11.5 per 100,000 inhabitants in 1994 to 21.7 in 2005 in Estonia and from 9.6 to 17.6 in Finland [13]. At the same time, SDR due to accidental poisoning by alcohol was 13.4 per 100,000 in Estonia and 9.4 in Finland compared with the EU average of 0.8 in 2005.

To obtain more insight into these issues, the objective of this paper was to describe and compare the proportion of abstainers, frequency and volume of alcohol consumption and beverage preferences in Estonia and Finland, and to examine drinking habits by socio-demographic factors in both countries in 1994-2006.

\section{Methods}

The study was based on the nationally representative cross-sectional postal surveys of the Finbalt Monitor project, which has been carried out every second year in Estonia and Finland since 1994. The national surveys were approved by the Tallinn Medical Research Ethics Committee in Estonia and the Ethical Committee of the National Public Health Institute in Finland. The target population of the Finbalt survey consisted of a simple random sample of the Estonian population aged between 16 and 64 and the Finnish population aged between 15 and 64 . The samples were based on the population registries of the respective countries. In 2006 the response rate was 59\% in Estonia and 65\% in Finland. A detailed description of the response rates by the study year can be found elsewhere [14]. In both countries the covering letter was formulated in such a way that a respondent provided informed consent at the time of returning the questionnaire. The methodology and the questionnaires used in the surveys were harmonized to provide comparability between the participating countries [15].

This paper deals with the 25-64-years-old population from surveys carried out every even year between 1994 and 2006 in Estonia and Finland.

Alcohol consumption was measured by means of frequency and quantity questions. Frequency questions were added to the questionnaires in 2000. Usual frequency of alcohol consumption was measured by the following three questions: "How often do you usually drink spirits (1), wine (2), beer (3)?" (In 2004, time reference 'during the past 12 months' was added to the questionnaire in Estonia). Until study year 2002, the possible responses were 'never', 'a few times a year', '2-3 times a month', 'once a week', '2-3 times a week', and 'daily'. In 2004, an additional option of the response '4-6 times a week' was added to the questionnaire in Estonia. In 2006 the options 'once a week' and '2-3 times a week' were replaced by the option 'a few times a week', and the option '4-6 times a week' was removed for Estonia. In this paper, the consumption of alcohol 'once a week' is reported in the group of alcohol intake as 'a few times a week'. The respondents who answered 'never' to all three questions were defined as current abstainers. Those respondents who answered 'once a week', 'a few times a week', '2-3 times a week', '4-6 times a week', or 'daily' to any type of alcohol beverage were defined as at least weekly alcohol consumers.

The amount of alcohol consumed per week during the years 1994-2006 was estimated from the answers to the following question: "How many glasses or bottles of the following alcoholic beverages have you had during the last seven days? "(Please mark 0 if you have not had any) (1) long drinks, cider_cans $(0.33 \mathrm{l})$, (2) beer_bottles $(0.5$ 1 in Estonia and 0.331 in Finland), (3) wine or equivalent glasses $(100 \mathrm{ml}$ in Estonia and $120 \mathrm{ml}$ in Finland), (5) strong alcohol _ shots $(4 \mathrm{cl})$. In Estonia, an option concerning the consumption of weak beer was added to the questionnaire in 2004; options concerning the consumption of weak, medium, and strong beer were added in 2006. In Estonia, drinking of cider was measured in cans $(330 \mathrm{ml})$, since it was regarded as belonging to the long drinks category. In Finland, the consumption of cider was measured in glasses $(120 \mathrm{ml})$ and was added as an option to the questionnaire in 1998.

On the basis of this information, the usual per week intake of pure alcohol was estimated among those who had drunk at least one portion of alcohol during the previous week. The typical reported amounts of alcohol con- 
sumed were converted from litres to grams of pure alcohol per week assuming that $0.5 \mathrm{l}$ of medium beer contained $20 \mathrm{~g}$ pure alcohol $(0.33 \mathrm{l} 12 \mathrm{~g}), 100 \mathrm{ml}$ of wine $10 \mathrm{~g}$, $120 \mathrm{ml}$ of cider $6 \mathrm{~g}$, and $4 \mathrm{cl}$ of spirits $13 \mathrm{~g} \mathrm{(16).} \mathrm{The} \mathrm{fol-}$ lowing criteria for predicting the risk of per week pure alcohol consumption were used: (1) medium risk $>280 \mathrm{~g}$ alcohol in males and $>140 \mathrm{~g}$ in females, (2) high risk $>420$ $\mathrm{g}$ in males and $>280 \mathrm{~g}$ in females [16].

The following socio-demographic factors were used in the analysis: age, ethnicity, marital status and education. Most of the variables analysed were self-explanatory. Age was calculated in full years (the birth year of the respondent was subtracted from the study year) and aggregated to 10-year age groups: 25-34, 35-44, 45-54 and 55-64. Ethnicity was measured by self-reported nationality (Estonian/Russian/other) in Estonia and by mother tongue (Finnish speaking/Swedish speaking/other) as revealed by information from the national population registry in Finland. Ethnicity was dichotomized as ethnic majority (Estonian in Estonia and Finnish speaking in Finland) and ethnic minority (Russian and other in Estonia, Swedish speaking and other in Finland). Marital status was categorized as married or cohabiting/single/ divorced or separated/widowed. In the Estonian questionnaire, education was measured as the highest completed educational level and the total number of years. In Finland, education was measured as the total number of years. The total number of years of education was missing for the study year 2004 in Estonia; the educational system has been different for Estonians and non-Estonians but changed considerably during the study period. For this reason, the highest completed educational level was preferred for use in this study. The educational levels were divided into three categories: high $(15+$ years), medium (10-14 years) and low (0-9 years).

\section{Statistical analysis}

A total of 10,340 Estonian questionnaires (4,239 men and 6,101 women) and 19,672 Finnish questionnaires (9,136 men and 10,536 women) were used in this study (Table 1). Data for men and women were analysed separately. Characteristics of the study sample, usual frequency, and volume of alcohol consumption were described by frequency tables.

Frequency of alcohol consumption in 2000-2006 was analysed on the basis of 6,916 Estonian (2,777 men and 4,139 women) and 11,034 Finnish (5,019 men and 6,015 women) questionnaires. Questionnaires with missing information concerning frequency of alcohol intake (1,005 in Estonia and 264 in Finland) were excluded.

Associations between the frequency of alcohol consumption and socio-demographic variables were estimated using logistic regression models. Consumption of any type of alcohol at least once a week (compared to less than once a week) was included in the model as a dependent variable; the study year and the socio-demographic characteristics (age group, ethnicity, marital status, and education) served as explanatory variables. The results of crude and fully adjusted logistic regression analysis were presented as prevalence odds ratios (POR) with 95\% confidence intervals (CI). Questionnaires that lacked information about the frequency of alcohol consumption and/ or socio-demographic factors (1,114 in Estonia and 471 in Finland) were excluded before logistic regression analysis.

Mean, standard deviation (SD), and median of pure alcohol consumption per week (in grams) in 1994-2006 were calculated for respondents who had drunk at least one portion of alcohol during the previous week. Questionnaires with missing or zero amounts of alcohol consumption (3,904 in Estonia and 5,595 in Finland) were excluded.

The effect of socio-demographic variables and the study year on the amount of pure alcohol consumption were assessed using linear regression models. The amount of pure alcohol consumption per week was included in the model as a dependent variable; the study year and the socio-demographic characteristics (age group, ethnicity, marital status and education) served as explanatory variables. The results of crude and fully adjusted linear regression models were presented as differences in the amount of pure alcohol consumption (in grams) with $95 \%$ confidence intervals. The $\mathrm{p}$-value for the linear trend between the amount of pure alcohol and the study year was calculated. Questionnaires that lacked information about socio-demographic factors (99 in Estonia and 234 in Finland) were excluded before linear regression analysis.

\section{Results}

Table 2 shows the socio-demographic characteristics of the sample. About three quarters of the respondents in both countries were married or cohabiting. Ethnic minority (mainly Russians) constituted nearly one third of the sample in Estonia. Only a few respondents represented ethnic minority in Finland. The proportion of respondents with a higher education was lower in Estonia than in Finland.

\section{Abstinence and frequency of alcohol consumption}

Overall, women in Estonia and Finland were about 1.5 times as likely as men to be current abstainers (5.8\% and $6.6 \%$ of men, $9.2 \%$ and $9.5 \%$ of women, respectively) in 2000-2006. There were no age differences between male abstainers in Estonia and Finland. Among women, the highest proportion of abstainers was in the oldest age group in both countries (15.6\% in Estonia and 16.0\% in Finland) (Figure 1). 
Table 1: Number of 25-64-year-old study sample in Estonia and Finland by survey year, 1994-2006

\begin{tabular}{|c|c|c|c|c|c|c|}
\hline \multirow[t]{2}{*}{ Study year } & \multicolumn{3}{|c|}{ Estonia } & \multicolumn{3}{|c|}{ Finland } \\
\hline & Men & Women & Total & Men & Women & Total \\
\hline 1994 & 474 & 632 & 1106 & 1340 & 1471 & 2811 \\
\hline 1996 & 531 & 700 & 1231 & 1383 & 1582 & 2965 \\
\hline 1998 & 457 & 630 & 1087 & 1394 & 1468 & 2862 \\
\hline 2000 & 435 & 655 & 1090 & 1310 & 1553 & 2863 \\
\hline 2002 & 420 & 635 & 1055 & 1230 & 1448 & 2678 \\
\hline 2004 & 1039 & 1431 & 2470 & 1259 & 1525 & 2784 \\
\hline 2006 & 883 & 1418 & 2301 & 1220 & 1489 & 2709 \\
\hline Total & 4239 & 6101 & 10340 & 9136 & 10536 & 19672 \\
\hline
\end{tabular}

Table 3 shows the frequency of consumption of different types of alcohol. Among the respondents in Estonia and Finland, the most popular alcohol beverage for at least weekly drinking was beer $(52.2 \%$ and $55.2 \%$ for men, $10.7 \%$ and $22.1 \%$ for women, respectively), followed by spirits among men $(22.4 \%$ and $20.6 \%$, respectively) and wine among women (9.8\% and $18.2 \%$, respectively). There were more daily beer drinkers, but fewer weekly beer drinkers among men in Estonia than in Finland. No difference was found between the two countries among men who drank spirits at least once a week, but almost twice as many Finnish men as Estonian men drank wine at least weekly. Nearly twice as many women drank beer or wine at least once a week in Finland as in Estonia.

Consumption of any type of alcoholic beverage at least weekly was similar among men in both countries $(62.9 \%$ and $62.3 \%$, respectively), but it was 1.6 times lower among women in Estonia than in Finland $(20.7 \%$ and $33.9 \%$, respectively). The proportion of people who drank any type of alcoholic beverage at least once a week varied across age groups; it was the highest among 35-44-yearold men and women in Estonia, but increased steadily with age among men in Finland, and reached the highest level among 45-54 year-old women in Finland (Figure 2).

The association between socio-demographic factors and frequency of alcohol drinking at least once a week was explored (Table 4). Compared to the first study year, weekly alcohol drinking was slightly higher among men in Estonia and Finland in 2004, but lower among men in Estonia in 2006. Compared to the youngest age group, alcohol consumption at least once a week was higher among men in all older age groups in Finland, but only among 35-44-year-old men in Estonia. The probability of drinking alcohol at least once a week was lower for ethnic minority men compared with similar individuals in ethnic majority in Estonia. No relationship between the fre- quency of alcohol consumption and ethnicity was established among men in Finland. In comparison with married/cohabiting men, drinking alcohol weekly or more frequently was lower among widowed men in Estonia and among single men in Finland. Frequency of alcohol drinking was lower among men with a basic education than those with higher education in Finland, but not in Estonia.

Alcohol consumption at least once a week was lower among women in Estonia in 2002 and 2006 than in the first study year (Table 4). Compared to the youngest age group, frequency of alcohol drinking was higher among women in all older age groups in Finland, but only among 35-44 year-old women in Estonia. Frequency of alcohol drinking was the lowest among women in the oldest age group in Estonia. Alcohol consumption at least once a week was more prevalent in ethnic minority women compared to the women in ethnic majority in Finland, but not in Estonia. Compared to married/cohabiting women, weekly alcohol consumption was slightly lower among divorced or separated women in both countries, among widowed women in Estonia and single women in Finland. Frequency of alcohol drinking was lower among women with secondary and basic education than higher education in both countries. After adjustment the association with a basic education appeared not to be significant among women in Estonia.

\section{Amount of pure alcohol consumed during previous week}

Table 5 shows the amount of pure alcohol drunk, the mean and median of pure alcohol consumed per week and the percentage of respondents with medium and high risks of drinking. Among men in Estonia, the median of pure alcohol consumed per week increased throughout the study period. The proportion of men with medium or high risk alcohol intake followed the same trend. Among men in Finland, the median of pure alcohol consumption 
Table 2: Characteristics of respondents in Estonia and Finland, 1994-2006

\begin{tabular}{|c|c|c|c|c|c|c|c|c|}
\hline \multirow{3}{*}{ Characteristic } & \multicolumn{4}{|c|}{ Estonia } & \multicolumn{4}{|c|}{ Finland } \\
\hline & \multicolumn{2}{|c|}{ Men } & \multicolumn{2}{|c|}{ Women } & \multicolumn{2}{|c|}{ Men } & \multicolumn{2}{|c|}{ Women } \\
\hline & $\mathbf{n}$ & $\%$ & $\mathbf{n}$ & $\%$ & $\mathbf{n}$ & $\%$ & $\mathbf{n}$ & $\%$ \\
\hline \multicolumn{9}{|l|}{ Age group } \\
\hline $25-34$ & 1072 & 25.3 & 1439 & 23.6 & 1920 & 21.0 & 2421 & 23.0 \\
\hline $35-44$ & 1136 & 26.8 & 1502 & 24.6 & 2345 & 25.7 & 2716 & 25.8 \\
\hline $45-54$ & 1061 & 25.0 & 1614 & 26.5 & 2678 & 29.3 & 2990 & 28.4 \\
\hline $55-64$ & 970 & 22.9 & 1546 & 25.3 & 2193 & 24.0 & 2409 & 22.9 \\
\hline \multicolumn{9}{|l|}{ Marital status } \\
\hline married/cohabiting & 3232 & 76.2 & 4046 & 66.3 & 6756 & 73.9 & 7813 & 74.2 \\
\hline single & 553 & 13.0 & 626 & 10.3 & 1556 & 17.0 & 1327 & 12.6 \\
\hline divorced/separated & 364 & 8.6 & 901 & 14.8 & 722 & 7.9 & 1064 & 10.1 \\
\hline widowed & 65 & 1.5 & 500 & 8.2 & 69 & 0.8 & 295 & 2.8 \\
\hline unknown & 25 & 0.6 & 28 & 0.5 & 33 & 0.4 & 37 & 0.4 \\
\hline \multicolumn{9}{|l|}{ Ethnicity } \\
\hline ethnic majority & 2951 & 69.6 & 4143 & 67.9 & 8587 & 94.0 & 9943 & 94.4 \\
\hline ethnic minority & 1254 & 29.6 & 1924 & 31.5 & 549 & 6.0 & 593 & 5.6 \\
\hline unknown & 34 & 0.8 & 34 & 0.6 & 0 & - & 0 & - \\
\hline \multicolumn{9}{|l|}{ Education } \\
\hline higher & 712 & 16.8 & 1410 & 23.1 & 2427 & 26.6 & 3577 & 34.0 \\
\hline secondary & 2655 & 62.6 & 3829 & 62.8 & 4075 & 44.6 & 4601 & 43.7 \\
\hline basic or less & 845 & 19.9 & 808 & 13.2 & 2473 & 27.1 & 2188 & 20.8 \\
\hline unknown & 27 & 0.6 & 54 & 0.9 & 161 & 1.8 & 170 & 1.6 \\
\hline Total & 4239 & 100 & 6101 & 100 & 9136 & 100 & 10536 & 100 \\
\hline
\end{tabular}

and medium risk alcohol drinking were stable, but the proportion of high risk alcohol drinkers per week increased slightly throughout the study period. Compared to Finland, the proportion of men with medium and high risk alcohol consumption per week was about the same in 1994, but nearly 1.5 times higher in 2006 in Estonia.

Median of pure alcohol consumed and medium risk alcohol drinking per week were lower among Estonian than Finnish women in 1994-2006 (Table 5). During the study period, the proportion of medium risk weekly alcohol drinkers increased among women in both countries. The proportion of women in Estonia whose amount of alcohol consumed per week was medium risk in 2006 was less than half that in Finland. The proportion of high risk drinking women remained stable throughout the study period in both countries.

The effect of the study year and socio-demographic factors on the amount of pure alcohol consumed per week was explored (Table 6). The years 1994-2006 showed an increasing trend in the amount of pure alcohol consumed per week among men in Estonia $(\mathrm{p}<0.001)$ but not in Finland ( $p=0.065)$. The amount of pure alcohol consumed per week was the lowest in the oldest age group among men in both countries. In Finland only, the amount of pure alcohol consumed weekly was lower in ethnic minority men. Compared to married/cohabiting men, pure alcohol consumed during the week was higher among divorced or separated men in both countries, but higher among single men in Finland only. Significantly more pure alcohol was consumed per week by less educated men in Estonia, but not in Finland.

The whole study period revealed an increasing trend in the amount of pure alcohol consumed per week among women in Estonia $(\mathrm{p}<0.001)$ and Finland $(\mathrm{p}=0.015)$ (Table 6). Compared to the women in the youngest age group, the amount of pure alcohol consumed per week was lower in the oldest age group in Estonia, but higher 
among 35-44 and 45-54-year-old women in Finland. The amount of pure alcohol consumed per week was higher among women of ethnic minority rather than women from ethnic majority in Estonia. This association was reversed in Finland. Pure alcohol consumption per week was higher among single and divorced or separated women than married/cohabiting women in Finland and lower among women with basic education than those with higher education.

\section{Discussion}

The present article focused on the results of alcohol consumption among 25-64-year-old respondents of Finbalt Monitor surveys carried out every even year in Estonia and Finland during the period 1994-2006.

\section{Limitations}

Before discussing the results, one has to consider the limitations of the survey. All questionnaire surveys of alcohol consumption are somewhat problematic because of inaccurate categorization of alcohol intake. People usually underestimate their consumption. In addition, heavy drinkers are generally less likely to participate in the surveys. Therefore the findings of the study need to be interpreted with caution. It is also important to consider that

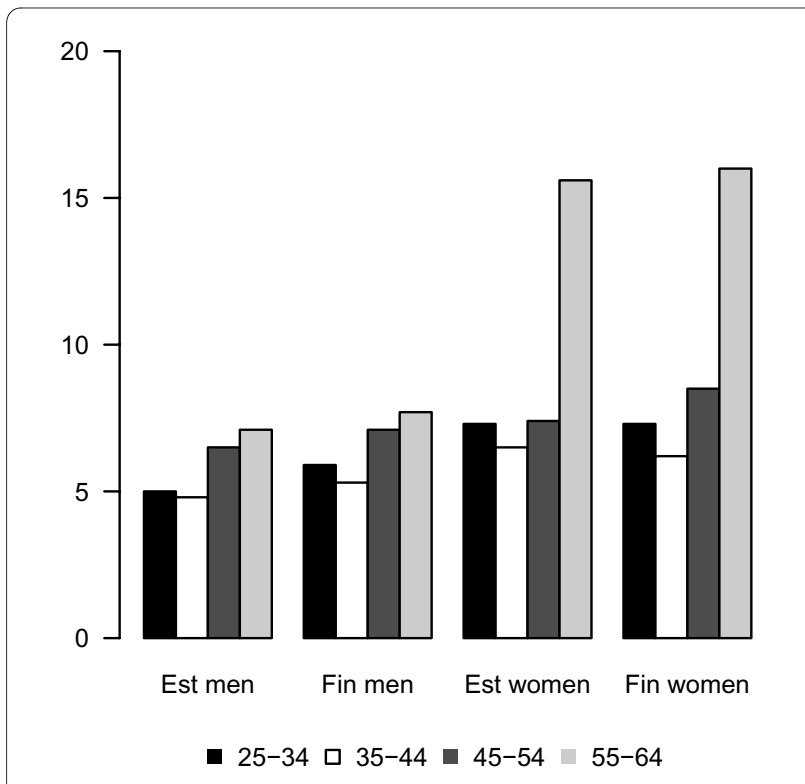

Figure 1 Proportion (\%) of current abstainers by gender, country and age group, Finbalt survey 2000-2006. Overall, women in Estonia and Finland were about 1.5 times as likely as men to be current non-drinkers of alcohol (5.8\% and $6.6 \%$ of men, $9.2 \%$ and $9.5 \%$ of women, respectively) in 2000-2006. The proportion of abstainers by gender was similar in both countries. There were no age differences between male abstainers in Estonia and Finland. Among women, the highest proportion of abstainers was in the oldest age group in both countries (15.6\% in Estonia and $16.0 \%$ in Finland). the degree of underreporting may vary among countries even if similar measurement techniques and standardized questionnaires are used. In this study, the questions concerning alcohol consumption varied slightly by study year and country. For example, questions about the frequency of alcohol consumption were formulated "How often do you drink spirits/wine/beer?" in Estonia in 2000 and 2002, "How often did you usually drink spirits/wine/beer during the last 12 month?" in Estonia in 2004 and 2006, and "How often do you usually drink spirits/wine/beer?" in Finland. Thus, caution must be exercised in making cross-country comparisons [17]. However, a major limitation was that because the survey was designed to obtain data on health behaviour in the adult population rather than alcohol consumption, the questions about drinking were basic and included no distinction between lifelong abstainers, former drinkers, or any of the standard instruments to detect hazardous drinking (excessive drunkenness, hangover, going to bed with one's clothes on because of drunkenness). Absence of data on the pattern of problem drinking means that the present study could underestimate the harmful drinking. Furthermore, the volume of alcohol consumed might have been underestimated because the figure was based on the question about alcohol consumption during the previous week. It may have excluded a rather significant proportion of less regular medium or high risk drinkers. Unfortunately, the common question "Have you consumed any alcohol during the previous year?" was not mandatory in the Finbalt survey questionnaire and was missing from the Estonian questionnaire. Therefore the frequency of drinking taking into account only the alcohol beverage most frequently consumed, was underestimated. Finally, the overall sample of the Finbalt survey was relatively large, but the small size of the samples per study year and the small size of certain sub-groups reduced the power to detect significant differences. For this reason pooled analysis rather than trend analysis was used to describe the association between alcohol consumption and socio-demographic factors. Despite these caveats, several inferences can be drawn.

\section{Abstinence and frequency of alcohol consumption}

A first crude indicator of alcohol consumption behaviour is the proportion of abstainers. The overall proportion of non-drinkers by gender did not differ between the countries. Moreover, Rehn et al [18] reported that the eight countries with the lowest proportions of abstainers are all northern European countries (including Estonia and Finland). In the present study, the proportion of abstainers was, not surprisingly, 1.5 times higher among women in both countries. This confirms the results of previous studies in Finland and Estonia [19]. Also, the NORBALT survey (1999) reported, that the non-drinking rate was 


\begin{tabular}{|c|c|c|c|c|c|c|c|c|c|c|}
\hline \multirow[t]{2}{*}{ Type of beverage } & \multicolumn{5}{|c|}{ Estonia } & \multicolumn{5}{|c|}{ Finland } \\
\hline & 25-34 & $35-44$ & $45-54$ & $55-64$ & Total & $25-34$ & $35-44$ & $45-54$ & $55-64$ & Total \\
\hline \multicolumn{11}{|c|}{ Men } \\
\hline \multicolumn{11}{|l|}{ Spirits } \\
\hline never & 9.3 & 7.3 & 9.1 & 11.3 & 9.2 & 10.1 & 10.0 & 11.2 & 10.5 & 10.5 \\
\hline a few times a year & 33.6 & 30.8 & 30.3 & 31.9 & 31.7 & 45.6 & 44.6 & 40.1 & 36.1 & 41.3 \\
\hline a few times a month & 40.6 & 36.9 & 36.0 & 32.7 & 36.7 & 32.6 & 28.9 & 25.5 & 25.3 & 27.7 \\
\hline a few times a week & 15.6 & 23.0 & 21.8 & 21.4 & 20.4 & 11.4 & 15.9 & 22.1 & 26.5 & 19.6 \\
\hline daily & 0.9 & 1.9 & 2.7 & 2.8 & 2.0 & 0.3 & 0.6 & 1.1 & 1.7 & 1.0 \\
\hline \multicolumn{11}{|l|}{ Beer } \\
\hline never & 11.3 & 9.5 & 15.2 & 18.1 & 13.3 & 12.7 & 9.8 & 11.6 & 12.7 & 11.6 \\
\hline a few times a year & 11.4 & 11.7 & 11.7 & 13.9 & 12.1 & 11.8 & 12.9 & 15.6 & 17.8 & 14.8 \\
\hline a few times a month & 25.7 & 21.2 & 20.1 & 22.0 & 22.3 & 23.0 & 19.6 & 15.9 & 16.6 & 18.4 \\
\hline a few times a week & 40.5 & 43.5 & 38.2 & 32.5 & 38.9 & 50.1 & 52.1 & 49.7 & 44.4 & 49.0 \\
\hline daily & 11.1 & 14.1 & 14.7 & 13.5 & 13.3 & 2.5 & 5.5 & 7.2 & 8.5 & 6.2 \\
\hline \multicolumn{11}{|l|}{ Wine } \\
\hline never & 21.5 & 23.6 & 26.8 & 32.4 & 25.7 & 25.1 & 19.5 & 23.5 & 21.9 & 22.4 \\
\hline a few times a year & 43.5 & 40.2 & 39.7 & 36.8 & 40.3 & 40.1 & 41.2 & 37.5 & 38.4 & 39.2 \\
\hline a few times a month & 27.6 & 23.0 & 21.3 & 19.8 & 23.1 & 23.0 & 22.1 & 18.0 & 15.6 & 19.4 \\
\hline a few times a week & 7.2 & 12.3 & 10.8 & 10.0 & 10.0 & 11.5 & 16.7 & 19.2 & 22.3 & 17.9 \\
\hline daily & 0.2 & 0.8 & 1.4 & 1.0 & 0.8 & 0.3 & 0.5 & 1.7 & 1.8 & 1.2 \\
\hline \multicolumn{11}{|c|}{ Women } \\
\hline \multicolumn{11}{|l|}{ Spirits } \\
\hline never & 30.5 & 25.9 & 21.7 & 30.7 & 27.1 & 20.8 & 22.2 & 23.6 & 32.3 & 24.7 \\
\hline a few times a year & 47.6 & 47.3 & 52.3 & 51.7 & 49.7 & 63.6 & 61.1 & 56.0 & 49.7 & 57.5 \\
\hline a few times a month & 17.6 & 21.5 & 20.6 & 14.8 & 18.6 & 13.6 & 12.5 & 14.2 & 11.9 & 13.1 \\
\hline a few times a week & 4.3 & 5.0 & 5.3 & 2.7 & 4.3 & 1.8 & 4.1 & 6.1 & 5.8 & 4.6 \\
\hline daily & 0.1 & 0.4 & 0.1 & 0.2 & 0.2 & 0.1 & 0.1 & - & 0.3 & 0.1 \\
\hline \multicolumn{11}{|l|}{ Beer } \\
\hline never & 43.2 & 43.0 & 47.3 & 60.8 & 48.4 & 44.4 & 31.5 & 31.8 & 44.0 & 37.4 \\
\hline a few times a year & 25.7 & 26.5 & 26.4 & 22.8 & 25.4 & 21.9 & 24.3 & 26.6 & 26.3 & 24.9 \\
\hline a few times a months & 20.1 & 16.3 & 15.3 & 10.3 & 15.6 & 18.4 & 17.5 & 16.0 & 10.6 & 15.6 \\
\hline a few times a week & 10.3 & 13.1 & 10.2 & 5.6 & 9.9 & 14.9 & 26.1 & 23.6 & 18.0 & 21.0 \\
\hline daily & 0.7 & 1.1 & 0.9 & 0.5 & 0.8 & 0.4 & 0.6 & 2.0 & 1.1 & 1.1 \\
\hline \multicolumn{11}{|l|}{ Wine } \\
\hline never & 11.5 & 13.4 & 18.4 & 28.9 & 18.0 & 18.7 & 15.5 & 19.5 & 23.8 & 19.4 \\
\hline a few times a year & 40.6 & 39.8 & 45.5 & 45.5 & 42.9 & 41.5 & 40.3 & 39.8 & 40.5 & 40.5 \\
\hline a few times a month & 36.8 & 33.0 & 27.3 & 20.1 & 29.4 & 27.3 & 24.2 & 20.4 & 16.5 & 22.0 \\
\hline a few times a week & 10.7 & 13.0 & 8.4 & 5.0 & 9.3 & 12.4 & 19.2 & 19.2 & 17.7 & 17.4 \\
\hline daily & 0.4 & 0.7 & 0.4 & 0.4 & 0.5 & 0.2 & 0.7 & 1.0 & 1.4 & 0.8 \\
\hline
\end{tabular}




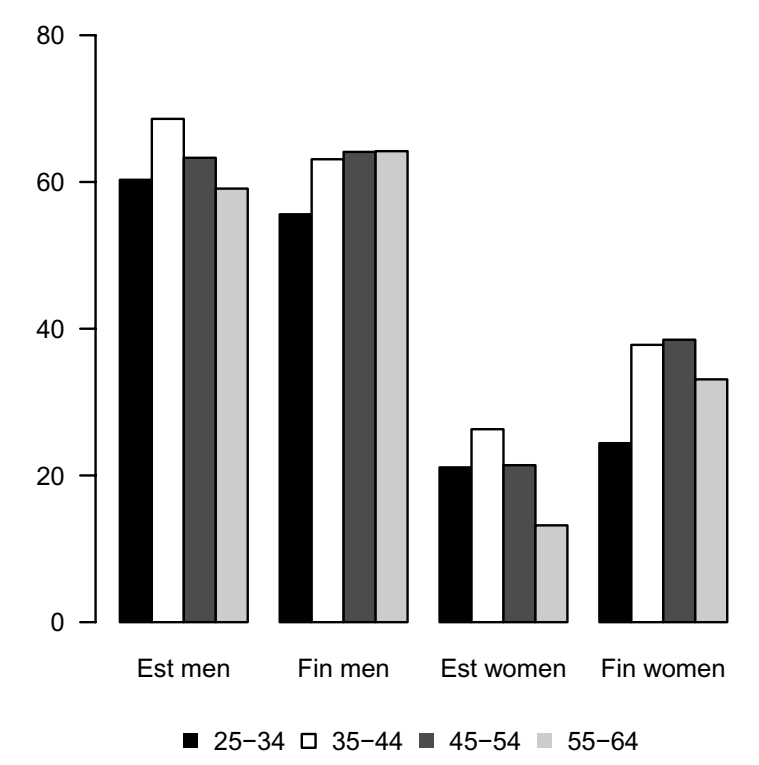

Figure 2 Proportion (\%) of respondents consuming alcohol at least once a week by gender, country and age group, Finbalt survey 2000-2006. Consumption of any type of alcoholic beverages at least weekly was similar among men in both countries ( $62.9 \%$ and $62.3 \%$, respectively), but it was lower among women in Estonia than in Finland (20.7\% and $33.9 \%$, respectively). Approximately three times as many men as women in Estonia and twice as many in Finland drank alcohol at least once a week. The proportion of people who drank any type of alcoholic beverages at least once a week varied across age groups. It was the highest in the age group 35-44 among men and women in Estonia but grew steadily with age among men in Finland, and reached a higher level among 35-54-year-old women in Finland.

much lower in men than in women $(10 \%$ and $23 \%$, respectively) in Estonia [20]. Thus, it seems that in Estonia the gender gap has decreased during the past ten years.

The proportions of abstainers by gender differed considerably between the countries, and this might be explained by their different traditions with respect to alcohol. For example, the gender gap has been small in countries such as Norway, Denmark, and Germany, but Sweden, the Netherlands and the United Kingdom revealed larger gender differences in the proportion of abstainers [19].

Overall, the preferred alcohol beverages were similar in Estonia and Finland, but the frequency of drinking each type of beverage and at least weekly consumption of any type of alcohol differed between the countries. There were very few daily drinkers in either country regardless of beverage or gender. The only exception to this pattern was beer drinking among men in both countries, but especially in Estonia. This could be explained by different attitudes towards life style and health in Estonia and Finland. Also, previous studies have shown that daily drinking was rather rare in the Baltic countries and Finland $[10,19]$. In addition, McKee et al [10] reported that the only group in which drinking was at all common was Estonian male beer drinkers (13\%). Countries can often be categorized as mainly beer, wine or spirits countries. The results of this study confirm that Estonia and Finland are primarily beer-drinking countries. They both used to be spirits-drinking countries. In Finland, the proportion consuming spirits was the highest until the 1990s [21]. Simpura et al [12] reported that the era of spirits-drinking as a dominant feature in the Scandinavian countries had already ended by the 1960s. In Estonia, spirits were the most popular type of alcohol beverages as recently as 1999. At the same time, the consumption of beer doubled among men in Estonia during 1994-1999 [20]. Nevertheless, spirits drinking did not disappear in these countries; only its relative position became weaker. The present study reported that more than a fifth of men in Estonia and Finland were at least weekly drinkers of spirits. As in to the Commonwealth of Independent States, this finding supports the assumption that the consumption of strong spirits is still common in Estonia [22]. While spirits drinking was low among women in both countries, the drinking of beer and wine at least weekly was more common among women in Finland. This could explain the higher prevalence of alcohol consumption among women in Finland.

Consumption of any type of alcohol beverage at least weekly was similar among men in Estonia and Finland, but it was much lower among women in Estonia than in Finland. Previous Estonian studies showed the same proportion of weekly alcohol drinkers [19]. The lower proportion of alcohol consumption at least once a week among women in Estonia could be explained by the fact that during the Soviet period alcohol consumption among women was low.

\section{Amount of alcohol consumed}

Throughout the study period, the proportion of medium risk drinkers increased among men in Estonia and among women in Finland. Prevalence of medium risk drinkers among women in Estonia decreased after the first study year, but increased during the succeeding years. In the first study year the proportion of medium and high risk drinkers among men was lower in Estonia than in Finland, but the final study year revealed the opposite. Prevalence of medium risk alcohol drinkers was lower among women in Estonia than those in Finland throughout the study period. According to the HFA database [3], there is some supporting evidence for this.

\section{Socio-demographic differences in the frequency of alcohol consumption and amount consumed}

In general, the socio-demographic factors influenced the frequency and amount of alcohol consumed differently among men and women in the two countries. No clearcut 
Table 4: Prevalence odds ratios (POR) and $95 \%$ confidence intervals (CI) for consuming any type of alcoholic beverage at least once a week by gender and country, 2000-2006

\begin{tabular}{|c|c|c|c|c|}
\hline \multirow[t]{2}{*}{ Characteristic } & \multicolumn{2}{|c|}{ Estonia } & \multicolumn{2}{|c|}{ Finland } \\
\hline & Crude POR & Adjusted POR* & Crude POR & Adjusted POR* \\
\hline \multicolumn{5}{|c|}{ Men } \\
\hline \multicolumn{5}{|l|}{ Study year } \\
\hline 2000 & 1 & 1 & 1 & 1 \\
\hline 2002 & $0.81(0.61-1.08)$ & $0.75(0.56-1.00)$ & $1.04(0.89-1.23)$ & $1.02(0.87-1.21)$ \\
\hline 2004 & $1.41(1.09-1.82)$ & $1.39(1.08-1.80)$ & $1.26(1.07-1.49)$ & $1.21(1.03-1.43)$ \\
\hline 2006 & $0.66(0.52-0.85)$ & $0.64(0.50-0.83)$ & $1.01(0.86-1.19)$ & $0.95(0.80-1.12)$ \\
\hline \multicolumn{5}{|l|}{ Age group } \\
\hline $25-34$ & 1 & 1 & 1 & 1 \\
\hline $35-44$ & $1.40(1.11-1.77)$ & $1.44(1.13-1.83)$ & $1.34(1.13-1.60)$ & $1.34(1.12-1.60)$ \\
\hline $45-54$ & $1.11(0.89-1.40)$ & $1.20(0.94-1.53)$ & $1.42(1.20-1.68)$ & $1.54(1.29-1.85)$ \\
\hline $55-64$ & $0.96(0.76-1.21)$ & $1.02(0.79-1.32)$ & $1.41(1.19-1.69)$ & $1.62(1.33-1.98)$ \\
\hline \multicolumn{5}{|l|}{ Ethnicity } \\
\hline ethnic majority & 1 & 1 & 1 & 1 \\
\hline ethnic minority & $0.56(0.47-0.67)$ & $0.53(0.44-0.63)$ & $1.02(0.80-1.30)$ & $1.01(0.78-1.29)$ \\
\hline \multicolumn{5}{|l|}{ Marital status } \\
\hline married/cohabiting & 1 & 1 & 1 & 1 \\
\hline single & $0.95(0.74-1.21)$ & $0.95(0.73-1.23)$ & $0.63(0.54-0.73)$ & $0.70(0.60-0.82)$ \\
\hline divorced/separated & $1.06(0.80-1.42)$ & $1.00(0.74-1.35)$ & $0.96(0.78-1.19)$ & $0.97(0.78-1.20)$ \\
\hline widowed & $0.45(0.22-0.91)$ & $0.41(0.20-0.84)$ & $1.24(0.54-2.86)$ & $1.20(0.51-2.78)$ \\
\hline \multicolumn{5}{|l|}{ Education } \\
\hline higher & 1 & 1 & 1 & 1 \\
\hline secondary & $1.10(0.89-1.36)$ & $1.08(0.87-1.35)$ & $0.98(0.85-1.12)$ & $0.92(0.80-1.06)$ \\
\hline basic or less & $0.99(0.76-1.29)$ & $0.97(0.73-1.29)$ & $0.66(0.56-0.78)$ & $0.56(0.47-0.67)$ \\
\hline \multicolumn{5}{|c|}{ Women } \\
\hline \multicolumn{5}{|l|}{ Study year } \\
\hline 2000 & 1 & 1 & 1 & 1 \\
\hline 2002 & $0.62(0.47-0.82)$ & $0.60(0.45-0.80)$ & $1.02(0.87-1.19)$ & $1.02(0.87-1.20)$ \\
\hline 2004 & $1.11(0.89-1.40)$ & $1.07(0.84-1.35)$ & $1.14(0.98-1.33)$ & $1.13(0.97-1.32)$ \\
\hline 2006 & $0.48(0.38-0.62)$ & $0.46(0.36-0.59)$ & $1.03(0.88-1.20)$ & $0.98(0.84-1.15)$ \\
\hline \multicolumn{5}{|l|}{ Age group } \\
\hline $25-34$ & 1 & 1 & 1 & 1 \\
\hline $35-44$ & $1.34(1.07-1.68)$ & $1.38(1.10-1.74)$ & $1.90(1.61-2.24)$ & $2.03(1.72-2.41)$ \\
\hline $45-54$ & $1.02(0.81-1.28)$ & $1.06(0.83-1.34)$ & $1.96(1.67-2.30)$ & $2.30(1.94-2.73)$ \\
\hline $55-64$ & $0.56(0.43-0.74)$ & $0.60(0.45-0.80)$ & $1.55(1.31-1.83)$ & $2.01(1.67-2.42)$ \\
\hline \multicolumn{5}{|l|}{ Ethnicity } \\
\hline ethnic majority & 1 & 1 & 1 & 1 \\
\hline ethnic minority & $0.92(0.76-1.11)$ & $0.87(0.72-1.07)$ & $1.46(1.16-1.84)$ & $1.43(1.13-1.82)$ \\
\hline \multicolumn{5}{|l|}{ Marital status } \\
\hline married/cohabiting & 1 & 1 & 1 & 1 \\
\hline single & $0.89(0.68-1.16)$ & $0.85(0.65-1.12)$ & $0.69(0.58-0.82)$ & $0.74(0.61-0.88)$ \\
\hline
\end{tabular}


Table 4: Prevalence odds ratios (POR) and $95 \%$ confidence intervals ( $\mathrm{Cl}$ ) for consuming any type of alcoholic beverage at least once a week by gender and country, 2000-2006 (Continued)

\begin{tabular}{lllll}
\hline divorced/separated & $0.76(0.59-0.98)$ & $0.77(0.60-1.00)$ & $0.85(0.70-1.02)$ & $0.79(0.66-0.96)$ \\
widowed & $0.51(0.34-0.76)$ & $0.65(0.43-0.99)$ & $0.74(0.50-1.10)$ & $0.73(0.49-1.08)$ \\
Education & & & & 1 \\
higher & 1 & 1 & $0.78(0.69-0.88)$ & $0.67(0.60-0.76)$ \\
secondary & $0.83(0.69-1.00)$ & $0.81(0.67-0.98)$ & $0.62(0.53-0.73)$ & $0.50(0.42-0.60)$ \\
basic or less & $0.65(0.46-0.90)$ & $0.77(0.55-1.09)$ & 1 \\
\hline
\end{tabular}

*Each POR was adjusted for all other characteristics in the table

trend was found in the frequency of alcohol consumption in Estonia and Finland during 2000-2006. The lower frequency of alcohol consumption in Estonia in the final study year might be explained by the replacement of the option 'once a week' with 'a few times a week' in the question about alcohol consumption frequency in the Estonian questionnaire in that year. Thus, some respondents who consumed alcohol once a week could answer that they had consumed alcohol only a few times a month in 2006. At the same time, the whole study period 19942006 showed an increasing trend in the amount of pure alcohol consumed by men in Estonia and by women in both countries. One reason for increasing trend in alcohol consumption could be liberal alcohol policy in both countries. Moreover, previous studies in Finland reported that in the long-term, alcohol consumption of women has increased relatively more than of men in Finland, even if drinking is still more common among men [23,24].

Compared to the youngest age group, frequency of alcohol consumption was more prevalent among both genders in all older age groups in Finland and among 35-44-year-olds in Estonia, but lower among the 55-64year-old women in Estonia only. The lower frequency of alcohol drinking in the youngest age group could be

Table 5: Mean and median pure alcohol consumption $(\mathrm{g})$ during the previous week and the proportion of medium and high risk drinkers (respondents who had drunk at least one portion of alcohol) by gender, country and study year, 19942006

\begin{tabular}{|c|c|c|c|c|c|c|c|c|c|c|}
\hline \multirow[t]{2}{*}{ Study year } & \multicolumn{5}{|c|}{ Estonia } & \multicolumn{5}{|c|}{ Finland } \\
\hline & $\mathbf{n}$ & $\begin{array}{c}\text { Mean (SD) g/ } \\
\text { week }\end{array}$ & $\begin{array}{c}\text { Median g/ } \\
\text { week }\end{array}$ & $\begin{array}{l}\text { Medium } \\
\text { risk* \% }\end{array}$ & $\begin{array}{l}\text { High } \\
\text { risk** \% }\end{array}$ & $\mathbf{n}$ & $\begin{array}{c}\text { Mean (SD) g/ } \\
\text { week }\end{array}$ & $\begin{array}{c}\text { Median g/ } \\
\text { week }\end{array}$ & $\begin{array}{l}\text { Medium } \\
\text { risk* \% }\end{array}$ & $\begin{array}{c}\text { High } \\
\text { risk }^{* *} \%\end{array}$ \\
\hline \multicolumn{11}{|c|}{ Men } \\
\hline 1996 & 363 & $112(110)$ & 78 & 7.4 & 1.9 & 1043 & $131(128)$ & 98 & 9.5 & 3.8 \\
\hline 1998 & 329 & $123(155)$ & 80 & 7.9 & 2.7 & 1131 & $143(137)$ & 105 & 12.0 & 3.7 \\
\hline 2000 & 329 & $147(185)$ & 100 & 9.7 & 6.1 & 1030 & $137(141)$ & 99 & 10.0 & 4.6 \\
\hline 2002 & 310 & 144 (157) & 97 & 11.3 & 4.5 & 970 & 139 (176) & 97 & 9.6 & 3.6 \\
\hline 2004 & 795 & 164 (169) & 113 & 14.8 & 6.4 & 1006 & $143(132)$ & 110 & 10.7 & 4.0 \\
\hline \multicolumn{11}{|c|}{ Women } \\
\hline 1994 & 300 & $43(67)$ & 26 & 4.3 & 1.0 & 915 & $57(54)$ & 38 & 6.9 & 1.0 \\
\hline 1996 & 334 & $35(35)$ & 26 & 2.7 & - & 996 & $62(62)$ & 48 & 7.5 & 1.2 \\
\hline 1998 & 337 & 39 (38) & 26 & 2.4 & 0.3 & 1008 & 63 (59) & 48 & 9.3 & 1.1 \\
\hline 2000 & 368 & $43(45)$ & 30 & 3.5 & 0.8 & 993 & $59(66)$ & 38 & 7.5 & 1.1 \\
\hline 2002 & 340 & $42(84)$ & 25 & 2.6 & 1.2 & 953 & $60(64)$ & 38 & 7.8 & 1.5 \\
\hline 2004 & 794 & $46(54)$ & 30 & 4.4 & 1.4 & 1059 & $64(64)$ & 48 & 9.5 & 1.1 \\
\hline 2006 & 789 & $49(73)$ & 30 & 4.7 & 1.0 & 995 & $67(77)$ & 48 & 10.0 & 1.7 \\
\hline
\end{tabular}

* $>280 \mathrm{~g}$ pure alcohol per week in men and $>140 \mathrm{~g}$ in women

** $>420 \mathrm{~g}$ pure alcohol per week in men and $>280 \mathrm{~g}$ in women 
Table 6: The effect of study year and socio-demographic factors on pure alcohol consumption (g) during the previous week (respondents who had drunk at least one portion of alcohol) by country and gender, 1994-2006

\begin{tabular}{|c|c|c|c|c|c|c|c|c|}
\hline \multirow[t]{3}{*}{ Characteristic } & \multicolumn{4}{|c|}{ Estonia } & \multicolumn{4}{|c|}{ Finland } \\
\hline & \multicolumn{2}{|c|}{ Crude estimate } & \multicolumn{2}{|c|}{ Adjusted estimate* } & \multicolumn{2}{|c|}{ Crude estimate } & \multicolumn{2}{|c|}{ Adjusted estimate* } \\
\hline & $\boldsymbol{\beta}$ & $(95 \% \mathrm{Cl})$ & $\boldsymbol{\beta}$ & $(95 \% \mathrm{Cl})$ & $\boldsymbol{\beta}$ & $(95 \% \mathrm{Cl})$ & $\boldsymbol{\beta}$ & $(95 \% \mathrm{Cl})$ \\
\hline \multicolumn{9}{|c|}{ Men } \\
\hline \multicolumn{9}{|l|}{ Study year } \\
\hline 1994 & ref & & ref & & ref & & ref & \\
\hline 1996 & -16 & $(-40,8)$ & -13 & $(-37,12)$ & -6 & $(-18,6)$ & -6 & $(-18,6)$ \\
\hline 1998 & -4 & $(-29,21)$ & -2 & $(-26,23)$ & 7 & $(-5,18)$ & 6 & $(-6,18)$ \\
\hline 2000 & 22 & $(-3,47)$ & 27 & $(2,52)$ & 1 & $(-11,13)$ & 0 & $(-12,12)$ \\
\hline 2002 & 16 & $(-9,42)$ & 18 & $(-7,43)$ & 2 & $(-10,15)$ & 2 & $(-10,14)$ \\
\hline 2004 & 36 & $(15,57)$ & 38 & $(17,59)$ & 7 & $(-5,20)$ & 8 & $(-5,20)$ \\
\hline 2006 & 37 & $(16,58)$ & 43 & $(22,64)$ & 8 & $(-5,21)$ & 7 & $(-5,20)$ \\
\hline $\mathrm{p}$-value for linear trend & & $<0.001$ & & $<0.001$ & & 0.054 & & 0.065 \\
\hline
\end{tabular}

Age group

25-34

ref

35-44

45-54

$55-64$

Ethnicity

$(-15,16) \quad 3$

$(-13,19) \quad 0$

$(-9,10)$

ref

$-5 \quad(-22,11) \quad-6$

$(-22,11) \quad 4$

$(-5,14)$

3

$(-7,13)$

$-42$

$(-60,-25) \quad-44$

$(-62,-25)$

$-22$

$(-32,-12)$

$(0,20)$

$(-25,-3)$

ethnic majority

ethnic minority

Marital status

married/cohabiting

single

divorced/separated

widowed

$$
\text { ref }
$$

$-7$

$(-20,6)$

ref

24

45

$-46$

$(24,66)$

$(-98,6)$

ref

higher

secondary

basic or less

21

16

$(6,37)$
$(-3,36)$

Study year

1994

1996

1998

2000

2002

2004

2006

$\mathrm{p}$-value for linear trend ref

$-8$

$-4$

0

$-1$

3

6

$\begin{array}{ll}(-18,1) & -8 \\ (-14,5) & -4 \\ (-9,9) & 1 \\ (-11,8) & 0 \\ (-6,11) & 4 \\ (-2,14) & 7\end{array}$

0.001
$(-18,7)$

ref

$-35$

$(-48,-21)$

ref

$-31$

$(-44,-17)$

ref

$(-6,31)$

$(23,64)$

38

$(29,48)$

ref

$(-80,24)$

$(49,73)$

$(-26,50)$

36

$(27,46)$

$(48,73)$

$(-15,61)$

12

ref

$(3,33)$

$(7,46)$

$(-3,13)$

$(-20,-2)$

$(-4,11)$

26

Women 
Table 6: The effect of study year and socio-demographic factors on pure alcohol consumption (g) during the previous week (respondents who had drunk at least one portion of alcohol) by country and gender, 1994-2006 (Continued)

\begin{tabular}{|c|c|c|c|c|c|c|c|c|}
\hline \multicolumn{9}{|l|}{ Age group } \\
\hline $25-34$ & ref & & ref & & ref & & ref & \\
\hline $35-44$ & -1 & $(-6,5)$ & -1 & $(-6,5)$ & 7 & $(3,11)$ & 8 & $(4,13)$ \\
\hline $45-54$ & -1 & $(-7,5)$ & -2 & $(-8,4)$ & 6 & $(2,10)$ & 9 & $(4,13)$ \\
\hline $55-64$ & -6 & $(-13,0)$ & -8 & $(-14,-1)$ & -6 & $(-11,-2)$ & -3 & $(-8,2)$ \\
\hline \multicolumn{9}{|l|}{ Ethnicity } \\
\hline ethnic majority & ref & & ref & & ref & & ref & \\
\hline ethnic minority & 6 & $(1,10)$ & 6 & $(2,11)$ & -8 & $(-14,-1)$ & -8 & $(-14,-1)$ \\
\hline \multicolumn{9}{|l|}{ Marital status } \\
\hline married/cohabiting & ref & & ref & & ref & & ref & \\
\hline single & 3 & $(-4,10)$ & 4 & $(-3,11)$ & 12 & $(7,17)$ & 12 & $(8,17)$ \\
\hline divorced/separated & 1 & $(-5,7)$ & 1 & $(-5,7)$ & 9 & $(4,14)$ & 9 & $(4,14)$ \\
\hline widowed & -1 & $(-9,8)$ & 0 & $(-9,9)$ & -2 & $(-11,8)$ & 3 & $(-7,13)$ \\
\hline \multicolumn{9}{|l|}{ Education } \\
\hline higher & ref & & ref & & ref & & ref & \\
\hline secondary & 1 & $(-3,6)$ & 1 & $(-3,6)$ & -1 & $(-5,2)$ & -1 & $(-5,2)$ \\
\hline basic or less & 6 & $(-2,14)$ & 9 & $(0,17)$ & -9 & $(-14,-5)$ & -7 & $(-12,-2)$ \\
\hline
\end{tabular}

explained by the irregularity of alcohol consumption among young respondents. The amount of pure alcohol consumed per week was higher among Finnish women in the age groups 35-44 and 45-54 than among the youngest age group. At the same time, compared to the youngest age group, the amount of consumed pure alcohol per week was lower in the oldest age group among men in both countries and among women in Estonia.

The increase of alcohol drinking among women over 35-year-old follows a longerterm trend in Finland, reflects more liberal attitudes towards alcohol consumption and the egalitarian position of women in society $[23,24]$. At the same time, low alcohol consumption among 55-64-year-old women in Estonia could be explained with traditionally low alcohol drinking habits among women during the Soviet period.

Alcohol consumption weekly or more frequently was lower among men, but the amount of pure alcohol consumed per week was higher among women of ethnic minority in Estonia. At the same time, McKee et al [10] found that weekly alcohol drinking was lower among non-Estonian men and women in Estonia in 1997. The inconsistency in the findings concerning the frequency of alcohol consumption among women might be explained by a time difference in these studies (they were conducted in different years). However, compared to ethnic majority in Finland, alcohol drinking at least once a week was more common among women, but the amount of pure alcohol consumed per week was lower among both genders of ethnic minority.

Frequency of alcohol consumption was slightly less pronounced among divorced or separated women in both countries and widowed respondents in Estonia. Single respondents drank less frequently but consumed more alcohol per week in Finland. Divorced or separated men in both countries, but women in Finland only showed similar drinking patterns in the amount of alcohol consumed per week. A previous report of the Finbalt study [14] also indicated that heavy drinking was more common among non-married people.

The present study showed that less educated respondents in Finland and women in Estonia drunk alcohol with lower frequency. The fact that McKee et al [10] found no association between education and weekly alcohol consumption in Estonia in 1997 could again be explained by the time difference in these studies. A greater weekly consumption of pure alcohol was associated with lower education among men in Estonia only. One could speculate that better educated adults drink alcohol more frequently than less educated ones but consume less alcohol per week. Also, a survey conducted in Izhevsk in Russia reported that lower education was strongly associated with hazardous drinking in working age men [25]. Nevertheless, women with a basic education consumed less pure alcohol per week than more highly educated women in Finland. This confirms the finding of Helasoja et al [14] that heavy drinking was 
more common among better educated adults in Finland, which is a typical drinking pattern in Northern Europe [26].

\section{Conclusion}

Although Estonia and Finland are neighbouring countries, they differed markedly in the frequency and amount of drinking, and in the association between alcohol consumption and socio-demographic factors. Alcohol consumption has increased in Estonia and Finland indicating that alcohol should be a concern for public health in this region. National alcohol policies should reflect the findings of alcohol epidemiology in order to reduce alcoholrelated harm in the population effectively.

\section{Competing interests}

The authors declare that they have no competing interests.

\section{Authors' contributions}

KP: made a substantial contribution to the conception and the design of the study, interpretation of the data, drafted the manuscript and has been involved in revising the manuscript critically. KR: participated in the design of the study, performed statistical analyses, has been involved in the interpretation of the data and in revising the manuscript critically. SH: has taken part in collecting the Finnish data and preparing the Finnish data set and designing the study, was involved in the interpretation of the data, and critically revised the manuscript. MT: principal investigator of the Finbalt study in Estonia was involved in the interpretation of the data and critically revised the manuscript. All authors read and approved the final manuscript.

\section{Acknowledgements}

The study was supported by the Estonian Science Foundation (grant ETF7416), the Estonian Ministry of Education and Science (target funding SF0940026s07 and SF0182648s04), and the Norwegian Financial Mechanism/EEA (grant EE0016). The authors thank professor Mati Rahu for valuable comments. His first comment was not accepted; otherwise this paper would never have materialized. The authors are grateful to the data base managers Risto Sippola in Finland and Tatjana Veideman in Estonia.

\section{Author Details}

${ }^{1}$ Department of Public Health, University of Tartu, Estonia, ${ }^{2}$ Estonian Centre of Behavioural and Health Sciences, Tallinn/Tartu, Estonia, ${ }^{3}$ Institute for Health Development, Tallinn, Estonia and 4 National Institute for Health and Welfare, Helsinki, Finland

Received: 6 May 2009 Accepted: 19 May 2010 Published: 19 May 2010

\section{References}

1. Silventoinen $\mathrm{K}$, Lahelma E: Health inequalities by education and age in four Nordic countries, 1986 and 1994. J Epidemiol Community Health 2002, 56:253-258.

2. Database of Statistics Estonia [http://www.stat.ee]

3. World Health Organization (WHO): European health for all database. [http://data.euro.who.int/hfadb/].

4. World Health Organization: WHO Expert Committee on problems related alcohol consumption. WHO technical report series 944. Second report 2007 [http://www.who.int/substance abuse/ expert committee alcohol trs944.pdf]. Geneva: World health Organization

5. Di Castenuovo A, Costanzo S, Bagnardi V, Donati MB, lacoviello L, de Gaetano G: Alcohol dosing and total mortality in men and women: an updated meta-analysis of 34 prospective studies. Arch Intern Med 2006, 11(166):2437-2445.

6. Rehm J, Mathers C, Popova S, Thavorncharoensap M, Teerawattananon Y, Patra J: Global burden of disease and injury and economic cost attributable to alcohol use and alcohol-use disorders. Lancet 2009, 27(373):2223-2233.

7. Leinsalu M: Social variation in self-rated health in Estonia: a crosssectional study. Soc Sci Med 2002, 55:847-861.

8. Chenet L, Leon D, McKee M, Vassin S: Deaths from alcohol and violence in Moscow: socio-economic determinants. Eur J Popul 1998, 14:19-37.

9. Leon DA, Chenet L, Shkolnikov VM, Zakharov S, Shapiro J, Rakhmanova G, Vassin S, McKee M: Huge variation in Russian mortality rates 1984-94: artefact, alcohol, or what? Lancet 1997, 350:383-388.

10. McKee M, Pomerleau J, Robertson A, Pudule I, Grinberga D, Kadziauskiene K, Abaravicius A, Vaask S: Alcohol consumption in the Baltic Republics. J Epidemiol Community Health 2000, 54:361-366.

11. Popova S, Rehm J, Patra J, Zatonski W: Comparing alcohol consumption in central and eastern Europe to other European countries. Alcohol Alcohol 2007, 42:465-473.

12. Simpura J, Tigerstedt $C$, Hanhinen $S$, Lagerspetz $M$, Leifman $H$, Moskalewicz J, Törrönen J: Alcohol misuse as a health and social issue in the Baltic Sea region. A summary of findings from the Baltica Study. Alcohol Alcohol 1999, 34:805-823.

13. World Health Organization: European mortality database (MDB). [http:/ /data.euro.who.int/hfamdb/J.

14. Prättälä R, Helasoja V, Finbalt g: Finbalt Health Monitor. Monitoring health behaviour in Finland and the Baltic countries. In Global behavioural risk factor surveillance Edited by: McQueen DV, Puska P. New York: Kluwer Academic/Plenum Publishers; 2003:57-72.

15. Helasoja V, Lahelma E, Prättälä R, Petkeviciene J, Pudule I, Tekkel M: The sociodemographic patterning of drinking and binge drinking in Estonia, Latvia, Lithuania and Finland, 1994-2002. BMC Public Health 2007, 7:241

16. World Health Organization: International guide for monitoring alcohol consumption and related harm Regional Office for Europe: Department of Mental Health and Substance Dependence, Non-communicable Diseases and Mental Health Cluster; 2000.

17. Pomerleau J, McKee M, Rose R, Haerpfer CW, Rotman D, Tumanov S: Hazardous alcohol drinking in the former Soviet Union: a crosssectional study of eight countries. Alcohol Alcohol 2008, 43:351-359.

18. Rehn N, Room R, Edwards G: Alcohol in the European Region - consumption, harm and policies Copenhagen: WHO Regional Office for Europe; 2001

19. Reitan TC: On the verge of EU membership: alcohol cultures in the Baltic Sea region in a European perspective. Contemporary Drug Problems 2004, 31:287-327.

20. Brunovskis A, Ugland T: Alcohol consumption in the Baltic States. Developments from 1994 to 1999 Norway: Institute for Applied Social Science; 2003.

21. Norström T, Ed: Alcohol in postwar Europe. Consumption, drinking patterns, consequences and policy responses in 15 European countries Sweden: National Institute of Public Health; 2002.

22. Pomerleau J, McKee M, Rose R, Haerpfer CW, Rotman D, Tumanov S: Drinking in the Commonwealth of Independent States - evidence from eight countries. Addiction 2005, 100:1647-1668.

23. Bloomfield K, Gmel G, Neve R, Mustonen H: Investigating gender convergence in alcohol consumption in Finland, Germany, the Netherlands, and Switzerland: a repeated survey analysis. Subst Abus 2001, 22:39-53.

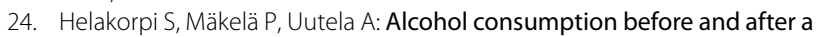
significant reduction of alcohol prices in 2004 in Finland: were the effects different across population subgroups? Alcohol Alcohol 2010 in press.

25. Tomkins S, Saburova L, Kiryanov N, Andreev E, McKee M, Shkolnikov V, Leon DA: Prevalence and socio-economic distribution of hazardous patterns of alcohol drinking: study of alcohol consumption in men aged 25-54 years in Izhevsk, Russia. Addiction 2007, 102:544-553.

26. Simpura J: Alcohol in eastern Europe: market prospects, prevention puzzles. Addiction 1995, 90:467-470

Pre-publication history

The pre-publication history for this paper can be accessed here: http://www.biomedcentral.com/1471-2458/10/261/prepub

doi: $10.1186 / 1471-2458-10-261$

Cite this article as: Pärna et al., Alcohol consumption in Estonia and Finland: Finbalt survey 1994-2006 BMC Public Health 2010, 10:261 